\title{
PELATIHAN KOMPUTER GRAFIS SEBAGAI UPAYA PENINGKATAN SOFTSKILL BIDANG DESAIN DAN EDITING PADA STT DUMAI
}

\author{
Tri Yuliati \\ Program Studi Teknik Informatika, Sekolah Tinggi Teknologi Dumai, Riau, Indonesia \\ *Penulis Korespodensi : triyuliati00@gmail.com
}

\begin{abstract}
Abstrak
Media grafis sebagai konten isi bisa dibilang lebih efektif dalam penyampaian pesan karena memadukan konten gambar dan berita.Salah satu aplikasi yang dapat digunakan dalam pembuatan media grafis adalah Photoshop dimana software ini mampu mengolah gambar dan pesan. Maka dari itu diperlukan kemampuan dalam mengolah dan pembuatan pesan yang benar dan baik dalam media grafis. Kegiatan pengabdian ini memiliki tujuan jangka panjang yaitu dosen dan karyawan bisa memiliki pengetahuan tentang desain grafis untuk membuat berbagai macam luaran seperti spanduk, udangan, editing photo dan lainnya. Untuk jangka pendeknya mampu mengoperasikan software photoshop dan bisa berkreasi. Kegiatan ini dilakukan praktek secara langsung di labolatorium komputer multimedia sehingga tidak hanya berupa teori tapi langsung bisa diterapkan dan ujicobakann. Karyawan bisa mengedit spanduk sendiri maupun pengumuman secara desain grafis untuk keperluan kampus STT Dumai kedepannya. Untuk pelatihan dosen tidak hanya jurusan teknik informatika saja tapi dari program studi lain bisa belajar menggunakan software photoshop untuk keperluan editing dan desain. Luaran akhir yang akan dicapai dari kegiatan ini adalah meningkatnya kemampuan peserta dalam penggunaan komputer sebagai alat pengembangan kreatifitas peserta dalam bidang desain
\end{abstract}

Kata kunci: Media Grafis; Desain; Photoshop.

\begin{abstract}
Graphic media as content is arguably more effective in delivering messages because it combines image and news content. One application that can be used in making graphic media is Photoshop, where this software is able to process images and messages. Therefore the ability to process and create messages that are true and good in graphic media is needed. This dedication activity has a long-term goal of which lecturers and employees can have knowledge about graphic design to make various kinds of outcomes such as banners, invitation, photo editing and others. For the short term is able to operate Photoshop software and can be creative. This activity is carried out directly in the practice of multimedia computer laboratories so that it is not only in the form of theory but can be directly applied and tested. Employees can edit their own banners as well as graphic design announcements for the future needs of the STT Dumai campus. For training lecturers not only majoring in informatics engineering, but from other study programs can learn to use Photoshop software for editing and design. The final output to be achieved from this activity is the increase in the ability of participants in using computers as a tool for developing participants' creativity in the field of design.
\end{abstract}

Keywords: Graphic Media; Design; Photoshop.

\section{PENDAHULUAN}

Pelatihan adalah suatu proses pembelajaran yang memperbanyak praktek dibandingkan teori yang dilakukan pelatih secara mendiri ataupun berkelompok untuk meningkatkan kemampuan dari individu ataupun kelompok. Tujuan dari pelatihan adalah individu maupun kelompok yang dilatih mempunyai penguasaan ketrampilan yang dapat dikuasai (Arumi \& Burhanuddin, 2018) Jenis pelatihan ada pelatihan wacana, ketrampilan, dan soft skill. Sedangkan cirri pelatihan antara lain terdapatnya suatu proses untuk meningkatkan ketrampilan yang dimiliki, materi yang disampaikan merupakan ketrampilan tertentu yang diperlukan, pelatihan dalam jangka waktu tertentu, dan proses pelatihannya dilakukan dengan mempelajari dan mempraktekkan sehingga menjadi kebiasaan (Budi Santoso, 2013)

Desain Grafis merupakan salah satu bidang Komunikasi Visual yang berkembang sangat pesat di Indonesia. Desain Grafis memiliki peranan yang penting dalam kehidupan baik di lingkungan masyarakat, akademis, industri, maupun pemerintahan (Kusrianto, 2007). Peranan desain grafis dalam kehidupan masyarakat tampak pada sosialisasi program Posyandu menggunakan media poster yang ditempel di papan 
pengumuman; di bidang akademis desain grafis terwujud dalam bulletin dan majalah seputar sekolah; di lingkungan industri menggunakan desain grafis dalam bentuk billboard untuk memperkenalkan produk; serta lembaga pemerintah menggunakan desain grafis dalam bentuk spanduk sebagai sosialisasi program Jalan Sehat yang diselenggarakan pemerintah kota/kabupaten.

Adobe Photoshop merupakan program pengolah desain grafis yang familier danpaling diminati di kalangan desain grafis. Program ini dapat digunakan dengan mudah karena terdapat tool-tool maupun efek yang menghasilkan berbagai bentuk desain yang inovatif dan ekspresif dengan dilengkapi komposisi warna yang bagus,serta adanya tool untuk membuat objek yang unik dan kreatif. Desain grafis atau rancang grafis adalah proses komunikasi menggunakan elemen visual, sepertitulisan, bentuk, dan gambar yang dimaksudkan untuk menciptakan persepsi akan suatu pesan yang disampaikan (Safanayong, 2006).

Masalah utama nya yang terjadi yakni dalam proses desain spanduk, poster, brosur dan informasi masih bergantung pada pihak percetakan sehingga untuk itu perlu disediakan dana untuk pelaksanaanya karena minimnya pengetahuan bagian akademis yang memiliki pengetahuan dibidang desain. Maka dari itu untuk menunjang kemampuan dan pengetahuan dibidang desain, maka diperlukan latihan dasar.

Sekolah Tinggi Teknologi Dumai memiliki 3 jurusan program studi yaitu Teknik Informatika, Tekik Industri dan Teknik Sipil selain itu juga memiliki karyawan dibidang akademis dengan sub bagian masing-masing. Guna menambah wawasan dan ketrampilan desain grafis bagi para karyawan dan dosen yang aktif dalam kegiatan publikasi informasi khususnya hal-hal yang berhubungan dengan penelitian dan pengabdian maupun kegiatan di STT Dumai, sehingga akan dapat memberikan nilai tambah pada aktivitas karyawan dan dosen.

\section{BAHAN DAN METODE}

Bahan yang digunakan dalam pelatihan ini meliputi laptop, proyektor dan aplikasi Adobe photoshop CS6 serta beberapa contoh softfile sertifikat dan photo yang akan digunakan untuk praktek langsung pengeditan. Metode yang digunakan dalam kegiatan pengabdian masyarakat adalah metode demonstrasi. Metode demonstrasi digunakan untuk menyajikan materi dengan memperagakan melalui penjelasan teori mengenai materi mengolah poster mengedit photo dan sertifikat dengan Aplikasi Adobe Photoshop CS6. Kemudian dilanjutkan dengan mempraktikan secara langsung pengolahan poster pengeditan photo dan sertifikat. Praktek langsung dilakukan pada komputer masing-masing dalam mengimplementasikan tool-tool apli-kasi Adobe Photoshop CS6.

\section{HASIL DAN PEMBAHASAN}

Pengabdian pada masyarakat ini dilaksanakan pada hari rabu tanggal 1 desember 2019 di laboratorium Sekolah
Tinggi Teknologi (STT) Dumai dan dihadiri oleh karyawan dan dosen STT Dumai. Materi pertama yang disampaikan oleh Ibu Tri Yuliati M.Kom tentang pengenalan dasar tentang Adobe Photoshop. Dalam sesi ini dosen dan karyawan diberi pengetahuan tentang bagian bagian dan tool yang ada dalam photoshop.

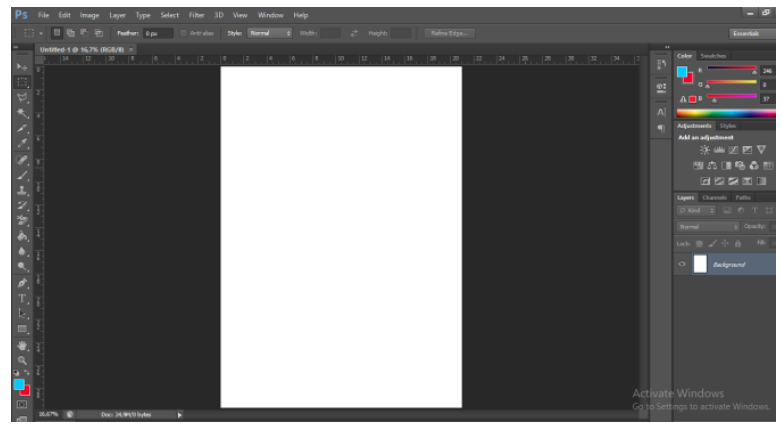

Gambar 1. Lembar Kerja Adobe Photoshop.

Materi selanjutnya adalah penjelasan tentang cara pembuatan spanduk, pengeditan sertifikat dan pembuatan pas photo. Pada sesi ini para peserta pengabdian praktek secara langsung di komputer dan dibimbing oleh Ibu Tri Yuliati, M.Kom.

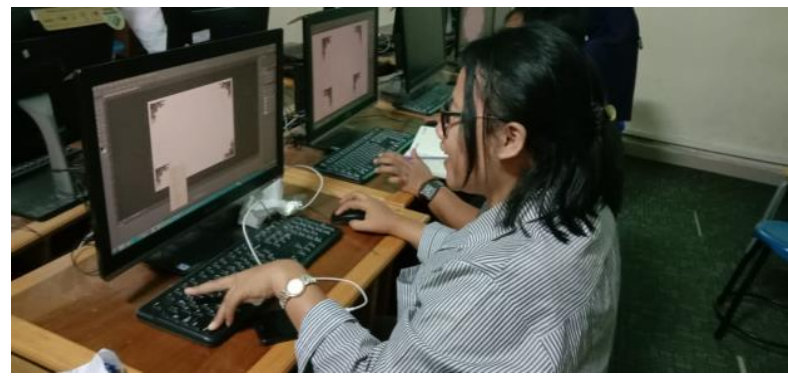

Gambar 2. Peserta Membuat Sertifikat.

Peserta mempraktikkan langsung bagaimana cara membuat sertifikat dengan cara melihat layar infokus dan langsung mengikuti arahan dari narasumber. Pada sesi pengeditan sertifikat, peserta diberikan modul untuk mengedit sebuah. Para peserta dibimbing dan diarahkan step by step.

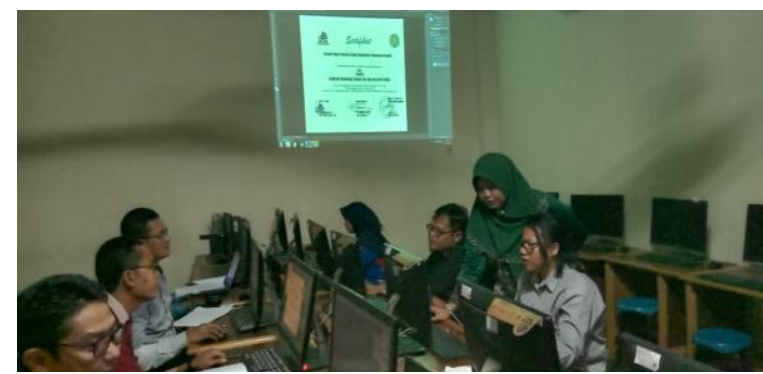

Gambar 3. Suasana Saat Mengajarkan Pembuatan Sertifikat.

Pemateri memberikan sebuah softfile contoh sertifikat yang akan diedit. Kemudian pemateri menunjukan caranya untuk mengedit sertifkat. Para peserta pelatihan sangat bersemangat dalam pengeditan sertifikat ini karena mereka mendapatkan ilmu baru tentang cara mengedit sertifikat. 


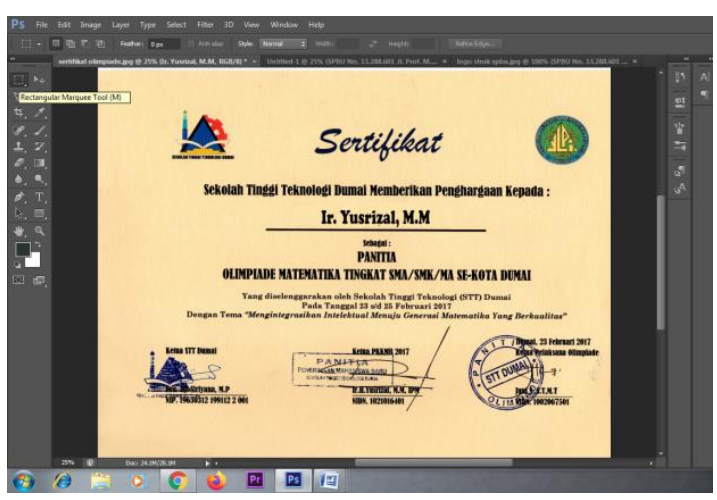

Gambar 4. Contoh sertifikat yang akan diedit.

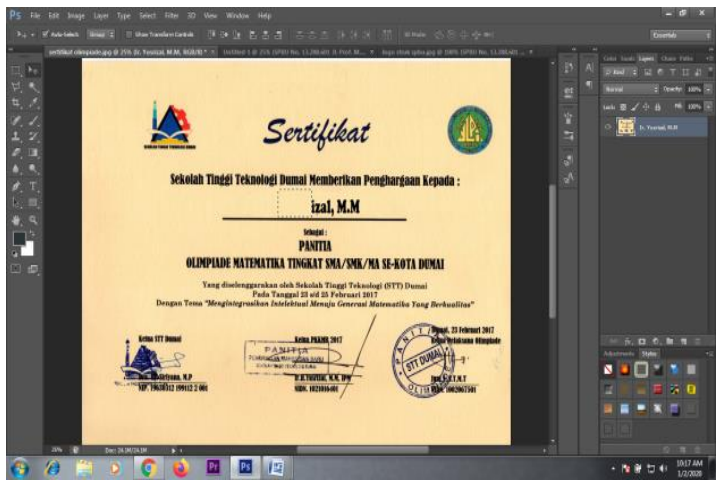

Gambar 5. Proses pengeditan sertifikat.

Sesi selanjutanya adalah membuat pas photo yang biasa digunakan untuk melamar pekerjaan. Ada beberapa pas photo yang biasa kita gunakan, mulai dari ukuran $2 \times 3$, $3 \times 4$ atau $4 \times 6$. Dalam pelatihan ini peserta diajari untuk membuat pas photo dan mengedit background sesuai yang diinginkan.

Peserta diberikan contoh softfile dari foto, kemudian dilanjutkan mengedit backgroud dari foto tersebut, baik itu warna merah atau warna biru. Setelah itu kemudian disetel ukuran fotonya tergantung dari kebutuhan. Mulai dari ukuran 2x3, 3x4 ataupun 4x6.

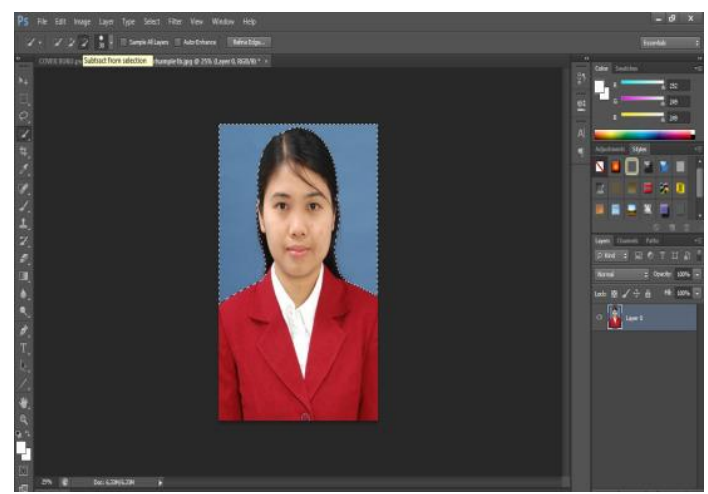

Gambar 6. Contoh poto yang akan diedit.

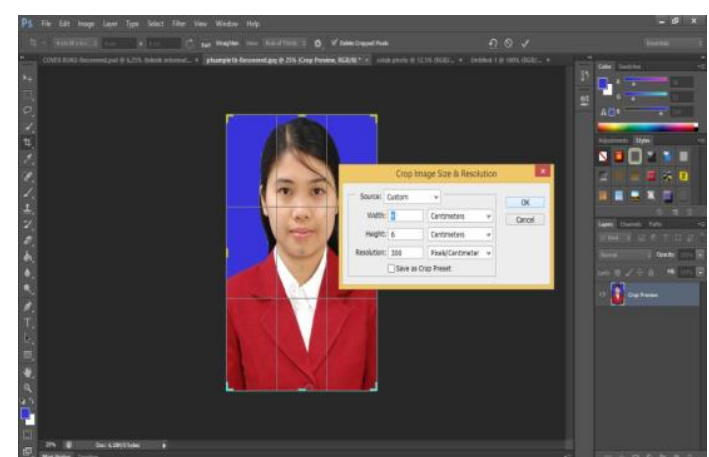

Gambar 7. Pengeditan backgroud warna biru.

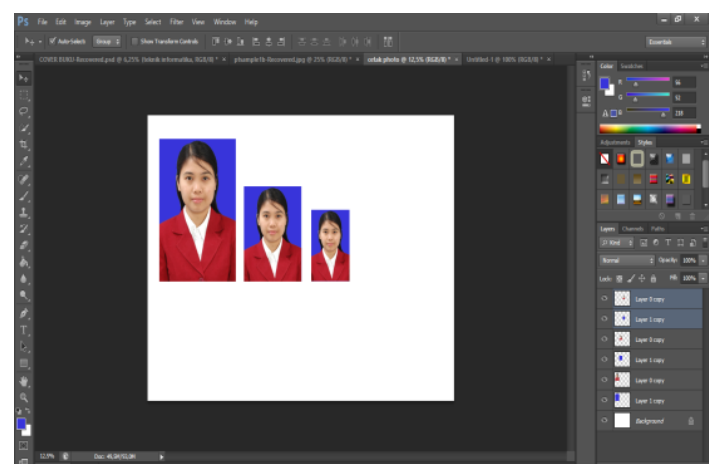

Gambar 8. Hasil pas photo ukuran 2x3 3x4, 4x6.

Secara umum kegiatan pengabdian ini berjalan lancar, dimulai dari kegiatan survei pendahuluan, pelaksanaan kegiatan pengabdian, sampai kepada penyusunan laporan. Berdasarkan diskusi yang diselenggarakan diperoleh kesimpulan bahwa para peserta pengabdian tersebut merasa senang dan puas. Hal ini terbukti denga $\mathrm{n}$ adanya permintaan dari para peserta agar kegiatan pengabdian ini tidak hanya diselenggarakan satu kali tetap harus berkelanjutan, mengingat pentingnya pembelajaran dan pengenalan design grafis bagi karyawan dan dosen stt dumai.

Faktor-faktor yang mendukung pelaksanaan pengabdian sehingga dapat terlaksana dengan lancar adalah Tingginya antusiasme peserta pengabdian untuk mengikuti pelatihan design grafis ini, Hasil yang diperoleh dari pengabdian ini adalah sebagai berikut :

1) Peserta yang hadir pada acara pengabdian itu sejumlah 22 orang dari 24 orang yang diundang. Alasan ketidakhadiran beberapa orang peserta tersebut adalah karena memiliki kegiatan lain dengan jadwal yang bersamaan dengan jadwal pengabdian.

Tabel 1. Daftar Peserta PPM.

\begin{tabular}{|c|l|c|c|}
\hline No & Jenis Kelamin & Jumlah & $\begin{array}{c}\text { Persentase } \\
(\%)\end{array}$ \\
\hline 1 & Laki-Laki & 8 & 36,36 \\
\hline 2 & Perempuan & 14 & 63,64 \\
\hline & Total & 22 & 100 \\
\hline
\end{tabular}


2) Materi yang diberikan pada pengabdian ini meliputi pengenalan adobe photoshop, pengeditan sertifikat, pembuatan spanduk dan pembuatan pas photo.

3) Para peserta yang mengikuti pelatihan merasa senang dan puas dengan kegiatan pengabdian ini, hal ini terlihat dari ungkapan kepuasan serta keantusiasan peserta mendengarkan dan bertanya berbagai hal tentang materi yang telah diberikan oleh para pengabdi.

4) Pada acara penutupan, hampir seluruh para peserta mengharapkan agar program serupa diadakan kembali untuk lebih memahami mengenai design grafis lebih lanjut.

\section{KESIMPULAN}

Berdasarkan uraian pelaksanaan kegiatan pengabdian ini, maka dapat ditarik kesimpulan sebagai berikut:

1) Kegiatan pengabdian ini dapat dikategorikan berhasil dari segi partisipasi peserta mengingat dari 24 calon peserta yang diundang yang hadir 22 orang.

2) Peserta pengabdian sangat merasa senang dan puas dengan kegiatan pengabdian dan meminta agar pengabdian serupadilaksanakan berkesinambungan mengingat pelatihan design grafis ini sangat membantu karyawan stt dumai dalam mengembangkan ide dibidang design grafis misalnya membuat spanduk, poster dan membuat pas photo.

3) Berdasarkan uraian pelaksanaan kegiatan pengabdian ini, dapat disimpulkan bahwa partisipasi peserta pengabdian sebesar $90 \%$. Peserta aktif bertanya dan mendengarkan berbagai hal tentang materi yang telah diberikan sampai kegiatan pelatihan berakhir. Peserta mengharapkan agar program serupa diadakan kembali dengan program pelatihan design grafis tingkat lanjut.

\section{UCAPAN TERIMA KASIH}

Ucapan terimakasih kami sampaikan kepada Sekolah Tinggi Teknologi (STT) Dumai melalui LPMM STT Dumai yang telah mendanai kegiatan pengabdian ini dan LPM UNIMED yang telah membantu mempublikasikan jurnal ini.

\section{DAFTAR PUSTAKA}

Arumi, E. R., \& Burhanuddin, A. (2018). Peningkatan kreativitas siswa sekolah menengah pertama dengan pelatihan corel draw. No. Issn: 2615 2118 Peningkatan, 1(2), 69-74.

Budi Santoso. (2013). Skema Dan Mekanisme Pelatihan Panduan Penyelenggaraan Pelatihan. Penerbit Yayasan Terumbu Karang Indonesia.

Kusrianto, A. (2007). Pengantar Desain Komunikasi Visual. Andi, Yogyakarta.

Safanayong, Y. (2006). Desain Komunikasi Visual Terpadu. Jakarta: Arte Intermedia. 